Citation: Buonanno F, Dolan JR, Esteban GF, Hine HN, Kamra K, Kosakyan

A, Miceli C, Samaritani E, Vannini C, Warren A, (2020) Protistological Science Dissemination. European Journal of Protistology, doi: https://doi.org/10.1016/j.ejop.2020.125729

\title{
Protistological Science Dissemination
}

Federico Buonanno ${ }^{a}$, John R. Dolan ${ }^{b}$, Genoveva F. Estebanc, Hunter N. Hinesc,d, Komal Kamrae, Anush Kosakyanf, Cristina Micelig*, Emanuela Samaritani ${ }^{\text {h }}$, Claudia Vannini ${ }^{\text {, }}$ Alan Warreni*.

aDepartment of E.C.H.T., University of Macerata, Macerata, Italy

bSorbonne Université, Laboratoire d'Océanographie de Villefranche-sur-Mer, CNRS UMR 7093, Station Zoologique, Villefranche-sur-Mer, 06230, France

cDepartment of Life and Environmental Sciences, Bournemouth University, Dorset BH12 5BB, UK

dHarbor Branch Oceanographic Institute at Florida Atlantic University, Fort Pierce, Florida, 34946, USA

eDepartment of Zoology, SGTB Khalsa College, University of Delhi, Delhi-110007, India fInstitute of Parasitology, Biology Centre Czech Academy of Sciences, 37005, Ceske Budejovice, Czech Republic

gSchool of Biosciences and Veterinary Medicine, University of Camerino, Camerino, Italy

hThe hidden world, PO Box 5941, Sheffield, S8 OPG, UK

iBiology Department, University of Pisa, Pisa, 56126, Italy

iDepartment of Life Sciences, Natural History Museum, London, SW7 5BD, UK

*Corresponding authors: cristina.miceli@unicam.it (Cristina Miceli), a.warren@nhm.ac.uk (Alan Warren)

\begin{abstract}
It is very rare to meet protistologists who are not passionate about their study subject. The vast majority of people, however, never get the chance to hear about the work of these researchers. Although every researcher working on protists is likely to be aware of this situation, efforts made and tools employed for dissemination of knowledge are rarely documented. Following a proposal by the Italian Society of Protistology, a workshop at the 2019 VIII European Congress of Protistology in Rome, Italy, was dedicated to protistological knowledge dissemination. Through the many interventions, we discovered the diversity of efforts to reveal the protistan world to the general public, including museum exhibitions and activities, public understanding of science events, citizen science projects, specific book publications, the use of protists in teaching at all levels from primary school children to university undergraduate students, and to a global audience via social media. The participation of the workshop delegates in the discussions indicated that presentations on the wonderful world of protists to the public not only increase the visibility and accessibility of protistology research, but are also very important for the scientific community. Here we report on some of the key aspects of the presentations given in the dissemination workshop.
\end{abstract}

Keywords: Citizen science, Protistology education, Public understanding of science, Science communication 


\section{Introduction}

Although protists comprise the vast majority of eukaryotic biodiversity and play numerous roles of major importance in ecological processes at the global scale, they are often forgotten and neglected, especially by the non-scientific community. One of the reasons for this is perhaps our limited efforts in regard to the dissemination of protistological knowledge to the public. If we compare the amount of material (movies, books, museum exhibitions, school workshops, games or any other leisure-time attractions) involving animals, plants, and fungi, versus protists, undoubtedly protists often stay invisible to the public. Nevertheless, with the growing awareness of the importance of knowledge dissemination for the sake and vitality of science itself, several public outreach ventures have been undertaken by protistologists, especially in recent years. Following a proposal by the Italian Society of Protistology, a workshop was convened at the 2019 VIII European Congress of Protistology in Rome, Italy, dedicated to protistological knowledge dissemination. In this paper, we summarize the main topics covered in the presentations given at the workshop and in the ensuing discussions that involved the active participation of an enthusiastic audience.

\section{Historical perspectives}

Efforts to popularise protists can be traced back to the 19th century (the Victorian Age in Great Britain) and the approaches used are still of some relevance. It was the time when relatively cheap mass-produced microscopes became available allowing microscopy to become a popular pastime. In public demonstrations and fairs, people first discovered, many with horror, the diversity of aquatic microorganisms in their drinking water (Fig. 1, left panel). Furthermore, the cholera epidemics of the 1840s and 1850s were eventually linked to some contaminated water supplies. Thus, aquatic microorganisms had a decidedly bad press.
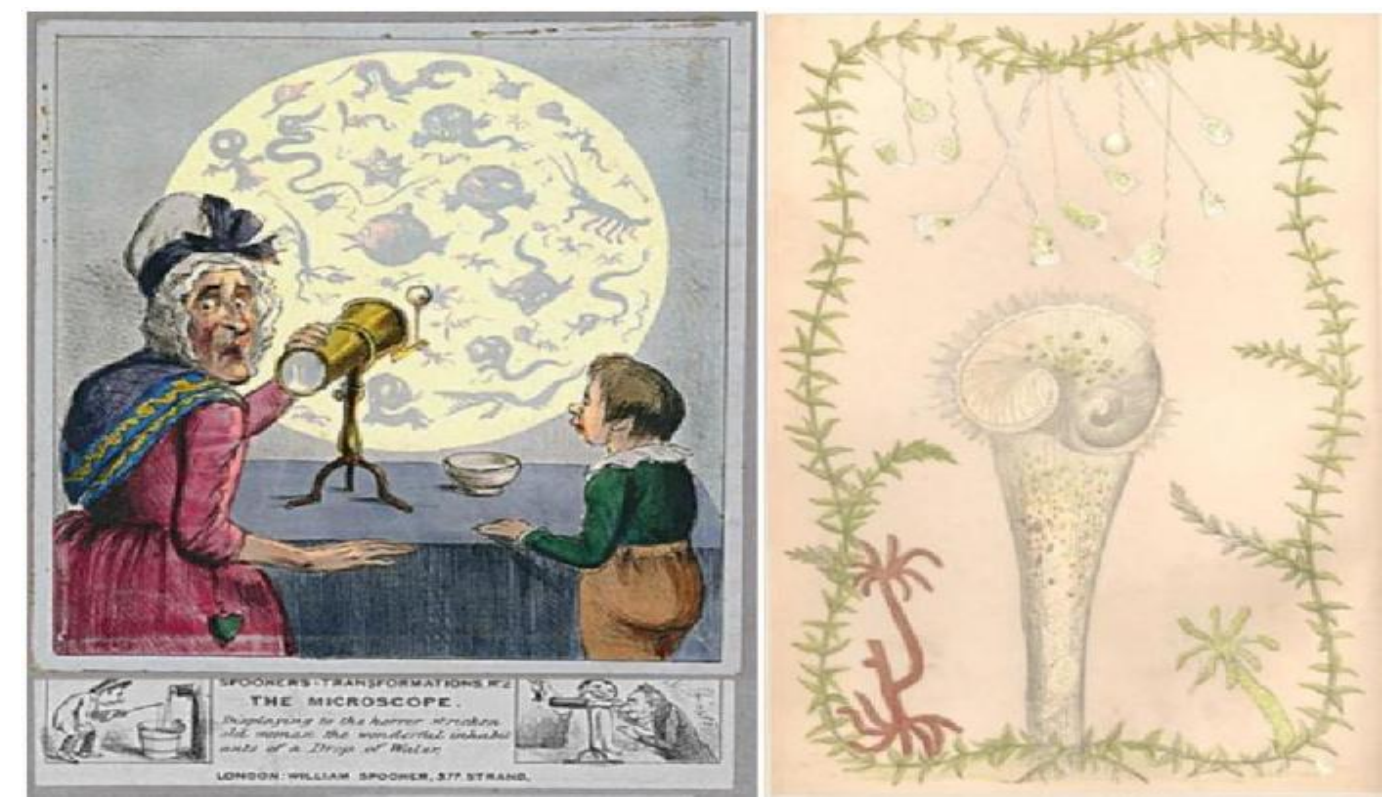

Fig.1. Left panel: an illustration by William Spooner, ca. 1835, showing the horror of discovering the microscopic inhabitants of a drop of water. Right panel: an illustration from Henry Slack's 1871 book, "Marvels of pond-life; or, A year's microscopic recreations among the polyps, infusoria, rotifers, waterbears and polyzoa", showing the beauty of aquatic microorganisms via an artistic composition of Stentor, Vorticella, algae and Hydra. 
Still, many books were published on microscopy aimed at general audiences, both adult and young. Some of these popular books are of particular interest as they included presentations of certain aquatic microorganisms, i.e., protists, in a very positive light (Dolan 2019 for full details). If one examines the approaches taken in these books to engage and convince the reader of the beauty and interest of the microscopic world, some approaches of relevance today are quite evident. The Victorian authors appealed to the imagination, to empowerment, and gave very practical instructions on how to see the invisible. Some such as Agnes Catlow described the microscopic world as a fantastic, marvelous, wonderland (Catlow 1851). Others, for example Edwin Lankester (Lankester 1863), emphasized empowerment as the microscope gave the power to see a previously invisible universe and presented artistic arrangements of protists (Fig 1 right panel). These Victorian approaches to popularizing much-maligned aquatic microbes, while valuable, are likely best suited to the very young as having the fewest preconceptions.

\section{Museums}

Today, museums play a key role in education and in raising public awareness on all aspects of the natural world. Coverage of protists in museum exhibitions is, however, patchy. Traditionally protist exhibits have comprised models such as the decimetrescale glass models made by Leopold and Rudolf Blaschka in the late 19th and early 20th century (Fig. 2; Web Ref. 1). The Upper Austrian Museum in Linz has made extensive use of protist models, both traditional and modern, in its exhibits, including a permanent exhibition on the nature of Upper Austria which opened in 2009 (Aescht 2018).

Furthermore, protist models are also used in Italy at the Natural History Museum of the University of Pisa and at the Protected Area of Torre del Cerrano, Teramo. As an alternative to models, exhibits such as that in the "Sant Oceans Hall" of the Smithsonian NMNH (Web Ref. 2), have sought to explain the importance of protists in terms of ecology (e.g., their role in the microbial loop), systematics (e.g., their diversity in the eukaryote Tree of Life) and value to society (e.g., their utility as markers in stratigraphy) by using SEM images and colour graphics. But perhaps the most innovative exhibits are those that encourage members of the public to explore protists in detail for themselves, either by microscopical examination of live specimens, e.g., in the 'Micro Aquarium" at Lake Biwa Museum, Japan (Web Ref. 3), and in the "Micropia" museum at Amsterdam, Netherland (Web Ref. 4), or as 3-D virtual images, e.g., in the 'Cabinet of Virtual Reality" at MNHN, Paris (Web Ref. 5). Many museums house collections of protist specimens. Traditionally, such specimens and their associated data were available only to specialists, usually via requests made to curators of such collections. Over recent years, however, museums are putting in ever-increasing efforts to digitize their collections and to make their data freely available on-line. Examples include the NHM, London, (Web Ref. 6), the NMHN, Paris, (Web Ref. 7) and the Smithsonian NMNH, Washington (Web Ref. 8). In addition to specimen metadata, all three of these databases include images of at least some of the specimens themselves. 


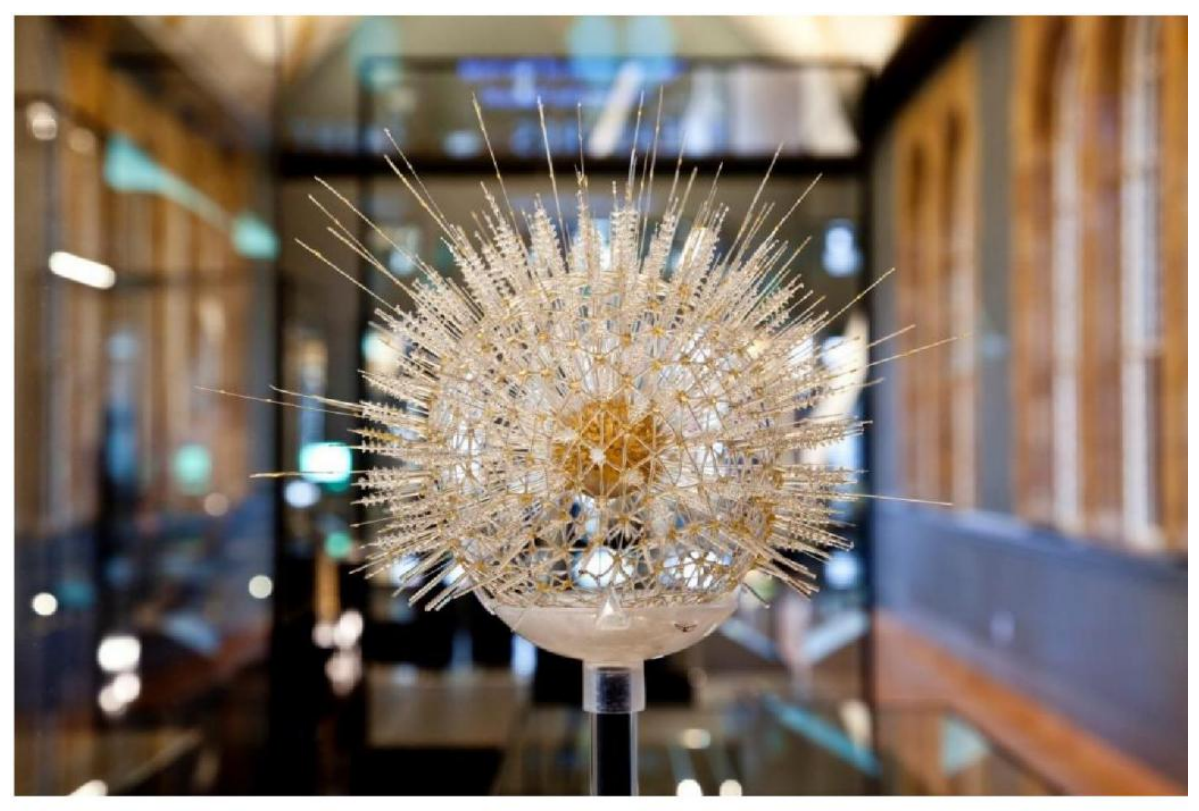

Fig. 2. Glass model of the phaeodarean Aulosphaera elegantissima Haeckel by Leopold and Rudolf Blaschka. (C) Trustees of the Natural History Museum, London, UK.

\section{Public events}

Another key way of disseminating knowledge and raising awareness of protists is via public events and activities. These may be small stand-alone events, components of annual large-scale events (e.g., European Researchers Night) or events and activities that form part of museum public programmes. Examples of the latter, both of which form part of the public offer of the NHM London, UK include: 'Using Microfossils to Age Clay" (Web Ref. 9), which guides participants through the processes of isolating and identifying fossil protists (mostly foraminiferans) from clay samples and using these to determine the age of the clay, and 'Crime Scene Live" (Web Ref. 10) which introduces participants to the collection and analysis of protist-based forensic evidence, such as the presence of diatoms in human bone marrow which indicates cause of death by drowning.

It is important to promote protistology and aquatic sciences by organising or taking part in public events in the local community. Most recently, the first Family Science Festival in the heart of Dorchester (UK) was led by one of the authors (G. Esteban) in collaboration with the County Museum, the Town Council and local schools, which saw over 2,000 people attending. One of the challenges is for children and their families to understand how to deal with something that is living but invisible to the naked eye. To solve this, hands-on, interactive activities are ideal, where children and the public in general are directly responsible for the event's success. After a short briefing, they are fully in charge of handling harmless protists, microscopes, slides, and pipettes. They also learn how to identify protists by following simple identification keys. From young children to nonagenarians (and beyond!), people go "wow" when they look down a microscope and see living protists. Watching a multitude of bright green Euglena in a small drop of water, the delicate shape of the colonial diatom Asterionella, the cytoplasm of Metamoeba flowing into its large emergent pseudopodia, or the majestic 
pink of the ciliate Blepharisma catching small flagellates with its oral cilia, is all too exhilarating for them to witness (Fig. 3). Whenever possible, activities that involve living protists are strongly encouraged. Any opportunity is suitable even if it is not strictly about science. In many cases the same activity can even fit for different kinds of public event, always remembering the WOW factor to impress children and adults, and to involve them in the activity so that they feel part of it.

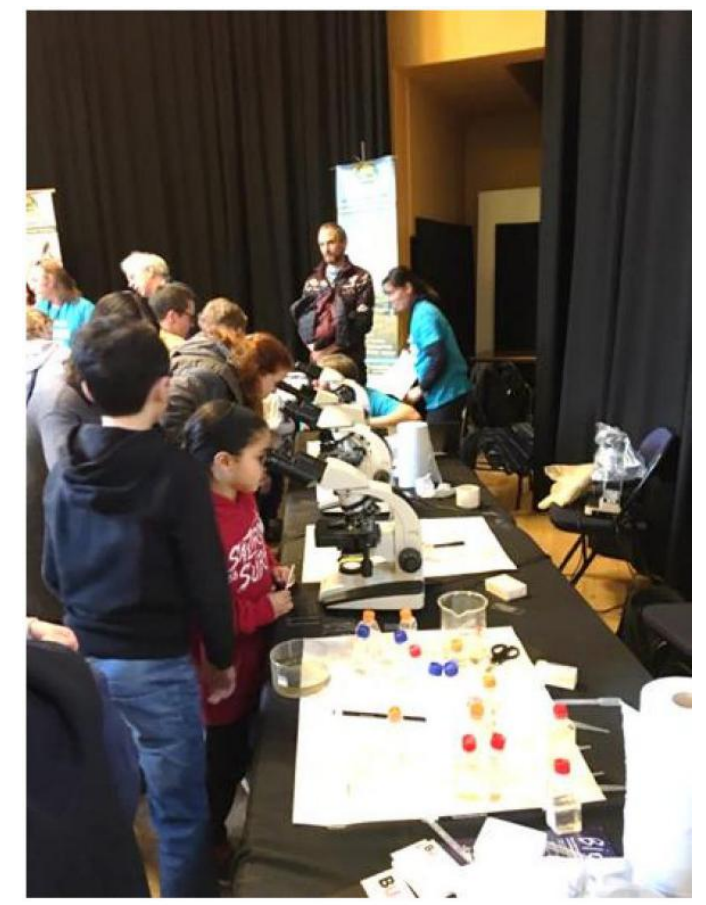

Fig. 3. Activity involving microscopes and protists at a family science festival organised by G. Esteban.

\section{Citizen science}

Citizen science is playing an increasingly important role, both in scientific research and public engagement. It has been defined as scientific work undertaken by members of the general public, often in collaboration with or under the direction of professional scientists and scientific institutions; the outcomes are often advancements in scientific research and an increase in the public's understanding of science (OED 2014). Compared to many macroscopic organism groups, citizen science projects involving protists are comparatively rare. One example is "Miniature Fossils Magnified", managed by the NHM, London (Web Ref. 11). In this project, ca. 5,000 microscope slides with foraminiferan specimens were scanned and images of the handwritten slide labels were made available on-line for members of the public to view and transcribe. The data collected were included in the NHM collections database and are now freely available via the NHM Portal (Web Ref. 6).

\section{Images and videomicroscopy}

Nowadays the development of modern microscopes and imaging techniques gives us the possibility to observe and document the world of protists with an ease that was not possible before. A vast amount of high quality, breathtakingly beautiful photographic and videographic material is being produced constantly in numerous protistological laboratories. This material can become a powerful and inspiring tool to introduce our 
organisms to both the non-scientific and scientific communities in different ways. For example, a source data pool could be created, providing access to all existing videographic and photographic material held in individual collections and websites. This could help scientific community to use all this amazing material for the workshops, exhibitions, lectures, books and booklets. The production of professional movies, for instance BBC nature documentary series, would probably be the most powerful way to disseminate protistological knowledge to the non-scientific public. Another strategy could be to create items for children using protist images. Hundreds of children's cartoons, books, games, toys, clothes, etc. are created with the images of animals, plants and fungi. Objects with protists images should be made to let protists be part of children's everyday life thus giving them the possibility to know about existence of the world beyond macrosopic organisms. A first attempt in the form of memory game was successful resulting in fast learning and lots of curiosity among groups of children (Anush Kosakian, unpublished). These efforts should be expanded.

\section{Children's books}

Popular literature is saturated with animal and plant books of all sorts and for all ages. A simple search on a global book distributor platform shows more than 70,000 results for animals, 50,000 for plants, 7,000 for fungi, and 6,000 for bacteria but only 90 books on protists. Looking specifically at children books, these numbers are even smaller, with only 14 on protists compared to 373 on bacteria and tens of thousands on plants and animals. Therefore, although children's books on protists are rare, some are available (for examples, see Hausmann and Machemer 2018). Authors of these books have generally taken one of two approaches: either the protists themselves are the main characters and tend to be cartoon-like and anthropomorphized, or the main characters are human (usually children) who become miniaturized to the size of the various protists that they encounter on their adventures. Examples include "Amoeba Hop" (Lavin, 2003) and "Aggi and the Mystic Boots" (Jones in press).

The recent actions, e.g., strikes, demonstrations etc., taken by young people all over the world in response to the climate crisis have highlighted the interest that this generation has in the health of the planet and its biodiversity. An illustrated book series entitled "The hidden world of microorganisms" aims at introducing children to the beauty, diversity and importance of protists. These books aim to reach children from all backgrounds and with diverse interests, to give them the opportunity to develop a natural curiosity, without compromising on the accuracy of the science. Examples include "The Hidden World of Diatoms" (Samaritani, 2018) and "The Hidden World of Testate Amoebae" (in preparation).

\section{Education}

The role of protists in science teaching at different levels in school and university systems deserves specific consideration. Science teaching is mainly transmissive, and the content of school science has an abstractness that could make it seem irrelevant. For this reason, learning science may be relatively difficult for some (Ajaja 2013). Many students today are learning science in classrooms where information is organized and presented to them by their teacher in a traditional way. The use of protists in the classroom as model organisms could be of considerable help to demonstrate biological sciences (Anderson and Druger 1997). Ciliated protists (ciliates) possibly represent ideal ecophysiological organisms to introduce students to the fundamentals of biology, such as physiology, ecology, systematics and evolution. Consequently, the use of ciliates 
in science laboratories may help students, even of young ages, to easily approach various important biological phenomena in a school context. In addition, it can lead to the removal of common misconceptions which often identify unicellular organisms as inferior, less-evolved and/or invariably harmful (Fig. 4).
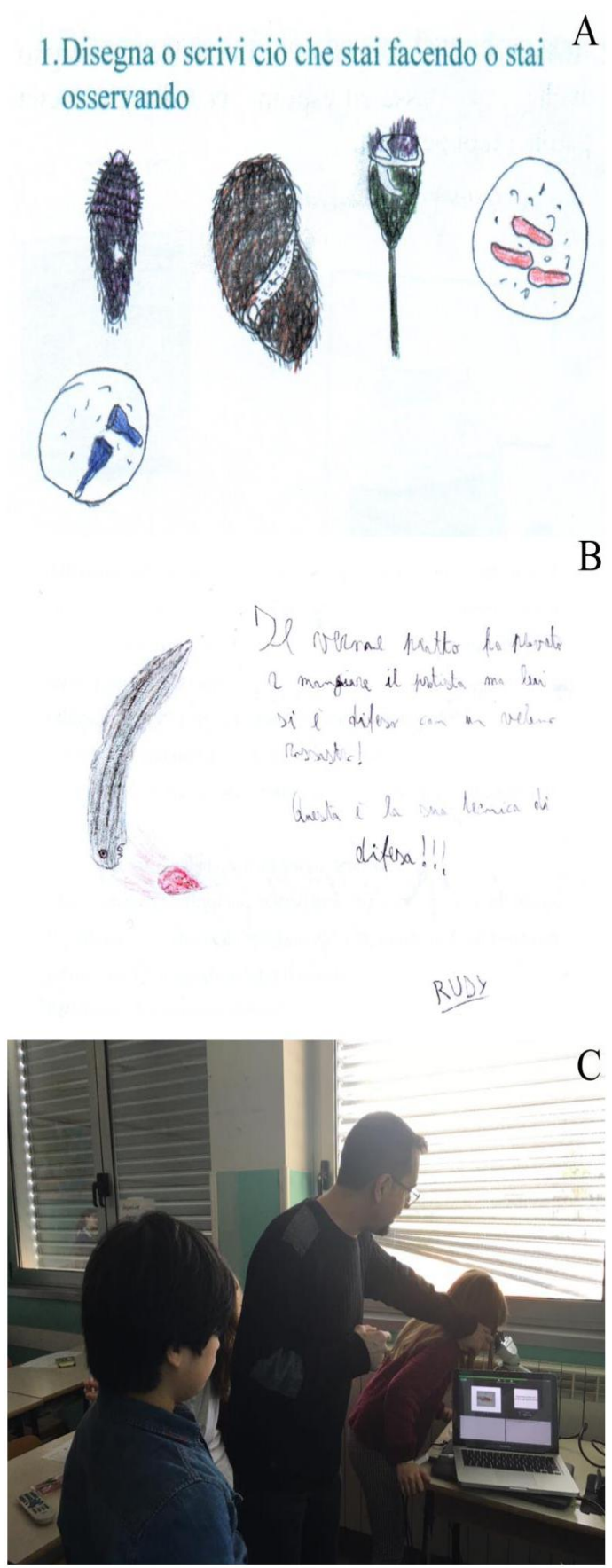

Fig. 4. (A) Drawing by an eight-year-old child of protists observed under the microscope. (B) Drawing and description made by an eleven-year-old child about the chemical defense response by a pigmented-toxic ciliate against a turbellarian flatworm. (C) Observation of protists in a fifth-grade class for biology teaching.

Curricula frequently have little space for protists. Those who choose to pursue life sciences in undergraduate (UG) programs may be exposed to some papers on 
protists, but the studies are often superficial with an emphasis on parasitic forms. Realizing that some UG students could use their mid-semester breaks and vacations during summer and winter to broaden their education, a group of teachers at Khalsa College, University of Delhi, India, began to engage them in small pilot projects involving free-living ciliates. The positive response from the students prompted the teachers to promote these projects further. Setting up a research laboratory in a UG college was the first step where students could pursue PhD programs and at the same time UG students could do small research projects. A strong Delhi group emerged when two former students, now teaching in different colleges, also established similar research laboratories. Importantly, the UG students get to make their own collections, isolate and identify protists (mainly ciliates considering that the involved laboratories presently focus on ciliate research). Some of the research projects done by UG students are published in peer-reviewed journals. The University of Delhi recognized these efforts and funded the UG student projects. Subsequently other colleges followed this initiative. Protistologists at Khalsa College and other colleges in the University of Delhi have also organised two meetings (in 2007 and 2018) each entitled "International Symposium on Ciliate Biology". These were largely aimed at UG students and teachers, giving them a platform to showcase the work they have done, interact with ciliatologists from around the globe, and encourage them to pursue this field of research after they graduate (Fig. 5, left panel). A workshop on "Ciliate tools and techniques" included in the 2018 symposium was well attended. Reports on both symposia have been published (Lynn 2007; Kamra et al. 2019). Media attention followed and, in recent times, two articles on the importance of protists have been published in the No 1 daily newspaper of India. Public attention is captured by pollution threatening biodiversity, including those of ciliates. The importance of protists as water-quality indicators greatly helps a general understanding of the valuable role they play in the ecosystem (Fig. 5, right panel).

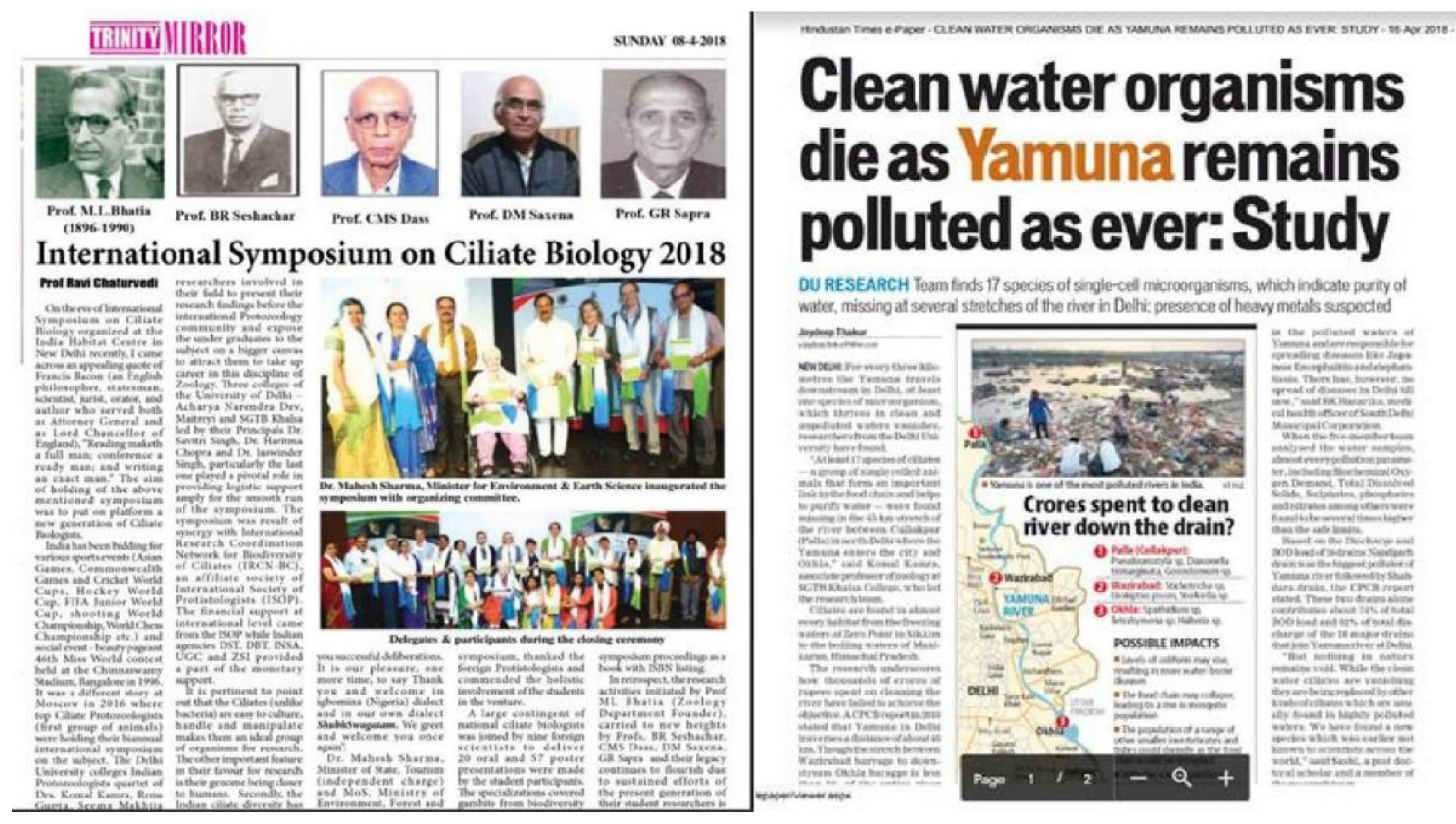

Fig. 5. Left panel: media attention following the organization of the International Symposium on Ciliate Biology, in 2018. Right panel: news on water pollution. 


\section{Social media}

Besides "traditional" media, like newspapers or television, an entire array of new media may now be fully used for protistological knowledge dissemination. Some successful attempts in this sense have already been made and many more should come. For example, "The hidden world of microorganisms" is also a blog and website (thehiddenworld.co.uk), a facebook page, a twitter (@thehiddenworld5) and Instagram ("thehiddenworldofmicroorganisms") profiles. Visibility on social media and the creation of an active community with the public is nowadays a necessary part of publication. As the entire world is increasingly becoming only a click away, it is important for scientists to continue to engage with this growing audience.

Social media was used during PhD research (Hines 2019a) to spread and share microbiology content (e.g. micrographs) taken during the project to a globallyinterested public. The platform that was selected for this objective was Instagram; the account created for this purpose was "Microbialecology". The account has amassed over 120,000 followers from around the world within two years. On the account, various micrographs and videos of microscopic organisms ranging from protists to tardigrades are shared along with brief descriptions. In addition to imagery of microbes, photos and short videos from field sample collection and laboratory research are also featured. Instagram has been shown to be a powerful tool in sharing microbiology to an increasingly global audience (Hines and Warring 2019; Hines 2019b). Scientists should use this and other popular social media platforms (e.g. YouTube) to share their research beyond the traditional scientific outputs. The demographics for social media trend towards a younger audience (Hines 2019b), a key social target for sparking interest in sciences. An interesting observation made on "Microbialecology" was the high number of followers from developing areas, who have vast interest in science but often lack access to research grade equipment many academics often take for granted. Scientists and amateurs alike in any field can share their research on social media. The larger audience that can be reached, the larger the potential for inspiring further interest in science to an increasingly global community.

\section{Artworks and commercial products}

Finally, numerous examples of protist-inspired artwork and commercial products can be found on-line, although Hausmann and Machemer (2018) provide an authoritative overview of historic and contemporary examples. Among the most impressive protistbased artworks are surely the large-scale (1-2 m) sculptures of foraminiferans that can be found in several places in China including Qingdao, Yantai and Zhongshan. These sculptures were inspired by the work of Prof Zheng Shouyi, Institute of Oceanology, Qingdao, who has made palm-sized models of about 250 species, some of which served as templates for the large-scale sculptures. For further details, see Web Ref. 12. Another remarkable example of protist-based artwork formed part of the "GEN 7" exhibition which opened in October 2011 at a church in Salzburg (Foissner 2012). "GEN 7" refers to chapter 7 of the Book of Genesis of the Bible, which narrates the story of the flood and Noah's Ark. The artwork in question took the form of an altarpiece which comprised a large (ca. $2 \mathrm{~m}$ ) illustration of the ciliate Metopus (Fig. 6). Occasionally, biologists turn their talents and knowledge to the production of protist-inspired commercial products such as jewellery, ornaments and even Christmas tree decorations. Examples include Kimberly Falk and Robert Kraus, whose products can be found at Web Refs. 13 and 14, respectively. 


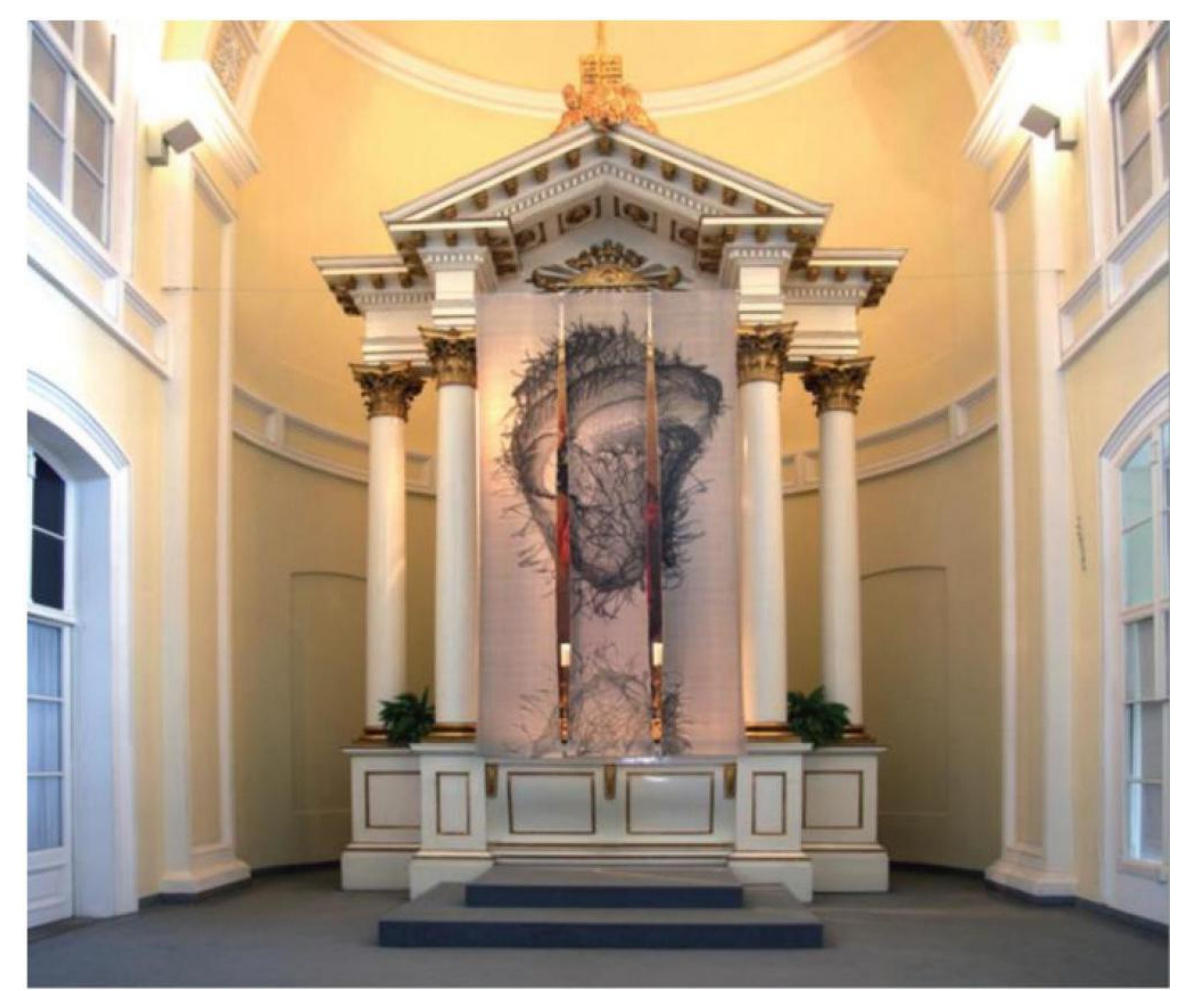

Fig. 6. A large-scale altarpiece of the ciliate Metopus at the „GEN 7" exhibition, Salzburg, Austria, 2011. From Foissner (2012).

\section{Conclusions}

In conclusion our advice is: if you are in doubt whether or not to organise an event/activity to promote knowledge and awareness of protists - go ahead and do it! What is important to remember is that in all outreach efforts we should allow ourselves to describe our organisms (or area of interest) with the enthusiasm and wonder that brought us into protistology. The experience is always rewarding; engaging with nonspecialist audiences helps to develop and improve communication and social skills, and it is great to be challenged by the public, as it makes us think about the importance of our own research. In other words, great fun for everybody!

\section{Acknowledgements}

The authors would like to thank the following for providing information: Marc Dellinger (MNHN, Paris, France), Allen Collins, (NMNH, Washington, USA), Yasushi Kusuoka (Lake Biwa Museum, Japan), Erna Aescht (Upper Austrian Museum, Linz, Austria), Juan Saldarriaga (UBC, Vancouver, Canada), Harriet Jones (UEA, Norwich, UK) and Klaus Hausmann.

\section{References}

Aescht, E., 2018. The "Microcosm Archive" at the Upper Austrian Museum in Linz (Austria): Microscopic specimens, protist library, profiles of main contributers and educational activities concerning unicellulars. Denisia 41, 295-482.

Ajaja, O.P., 2013. Which strategy best suits biology teaching? Lecturing, concept mapping, cooperative learning or learning cycle? Electron. J. Sci. Educ. 17, 1-37.

Anderson O.R., Druger M., 1997. Explore the world using Protozoa, 1st ed. VV. AA., editors, joint publication of NSTA and Society of Protozoologists, Arilngton, Virginia, USA. 
Catlow, A., 1851. Drops of Water: their Marvellous and Beautiful Inhabitants Displayed by the Microscope, Reeve and Benham,London.

Dolan, J.R., 2019. From the popularization of microscopy in the Victorian Age: A lesson for today"s "outreach". Protist 170, 319-327.

Foissner, W., 2012. Ein Ciliot ols Afiorbild und Protisten in der Oper. Mikrokosmos 101, 82-84.

Hausmann, K. and Machemer, H., 2018. The microcosm under the microscope: a passion of amateurs and experts. Denisia 41, 1-46.

Hines, H., 2019a. The biogeography, phylogeny, and dispersal of freshwater and terrestrial free-living ciliates in Florida, USA (Doctoral dissertation, Bournemouth University).

Hines, H., 2019b. Cell-fies: sharing microbiology with global audiences through Instagram. FEMS Microbiol. Lett. 366 (16), doi: 10.1093/femsle/fnz205.

Hines, H. and Warring, S., 2019. How we use Instagram to communicate microbiology to the public. Nature 2019 - Nature Careers Community, doi: 10.1038/d41586-019-00493-3.

Jones, H., (in press). Aggi and the Mystic Boots, Paramecium Press Ltd, Norwich, UK.

Kamra, K., Kaur, H., Na, S., Abraham, J.S., Somasundaram, S., Makhija, S., Toteja, R. Warren, A and Gupta, R. 2019. Symposium report: International Symposium on Ciliate Biology, India Habitat Centre, New Delhi, India, 04-06 April 2018. J. Eukaryot. Microbiol. doi:10.1111/jeu.12773

Lankester, E., 1863. Half-hours with the Microscope; Being a Popular Guide to the Use of the Microscope as a Means of Amusement and Instructions, Robert Harwick, London, UK.

Lavin, C., 2003. Amoeba hop. Puddle Jump, Piermont, NY, USA.

Lynn, D.H., 2007. Meeting report: International Symposium on Ciliate Biology held at Sri Guru Tegh, Bahadur (SGTB), Khalsa College, University of Delhi, February 6-7, 2007. Protist 158, 259-261.

OED, 2014. Oxford English Dictionary, Oxford University Press, Oxford, UK.

Samaritani, E., 2018. The hidden world of diatoms. Ed. The hidden world, Sheffield, UK.

\section{Web references:}

1. https://www.youtube.com/watch?v=aI83KEkUrTE, Natural History Museum (London, UK) channel, last access 2020-05-13

2. https://naturalhistory.si.edu/exhibits/sant-ocean-hall, Smithsonian National Museum of Natural History (Washington, DC, USA), last access 2020-05-13

3. https://www.biwahaku.jp/english/, Lake Biwa Museum (Oroshimo, JPN), last access 2020-05-13

4. https://www.micropia.nl/en/, Micropia Museum (Amsterdam, NL), last access 2020-05-

13

5. https://www.mnhn.fr/en/visit/lieux/cabinet-realite-virtuelle-cabinet-virtual-reality, National Museum of Natural History (Paris, FR), last access 2020-05-13

6. https://data.nhm.ac.uk/, Natural History Museum (London, UK), last access 2020-05-13

7. https://www.mnhn.fr/en/collections/collection-groups, National Museum of Natural

History (Paris, FR), last access 2020-05-13

8. https://collections.nmnh.si.edu/search/, Smithsonian National Museum of Natural

History (Washington, DC, USA), last access 2020-05-13

9. https://www.nhm.ac.uk/natureplus/blogs/micropalaeo/2013/09/17/microfossils-forschools.html, last access 2020-05-13

10. https://www.nhm.ac.uk/events/crime-scene-live.html, Natural History Museum (London, UK), last access 2020-05-13

11. https://www.nhm.ac.uk/take-part/citizen-science/miniature-fossils-magnified.html, Natural History Museum (London, UK), last access 2020-05-13

12.

https://cushmanfoundation.allenpress.com/Resources/WorldsFirstForaminiferalSculpturePark , last access 2020-05-13

13. https://www.shapeways.com/shops/ontogenie, last access 2020-05-13

14. https://www.micrasterias.de/einzeller/, last access 2020-05-13 